\title{
Article \\ Mosaic Segmental and Whole-Chromosome Upd(11)mat in Silver-Russell Syndrome
}

\author{
Laura Pignata $^{1}\left({ }^{1}\right.$, Angela Sparago $^{1}\left(\mathbb{D}\right.$, Orazio Palumbo $^{2}\left(\mathbb{D}\right.$, Elena Andreucci $^{3}\left(\mathbb{C}\right.$, Elisabetta Lapi $^{3}$, \\ Romano Tenconi ${ }^{4}$, Massimo Carella ${ }^{2}$ (D) Andrea Riccio ${ }^{1,5, *(D)}$ and Flavia Cerrato ${ }^{1}$ (D) \\ 1 Department of Environmental Biological and Pharmaceutical Sciences and Technologies (DiSTABiF), \\ Università degli Studi della Campania "Luigi Vanvitelli", 81100 Caserta, Italy; \\ laura.pignata@unicampania.it (L.P.); Angela.sparago@unicampania.it (A.S.); \\ flavia.cerrato@unicampania.it (F.C.) \\ 2 Division of Medical Genetics, Fondazione IRCCS "Casa Sollievo della Sofferenza", \\ 71013 San Giovanni Rotondo, Italy; o.palumbo@operapadrepio.it (O.P.); m.carella@operapadrepio.it (M.C.) \\ 3 Medical Genetics Unit, Meyer Children's Hospital, 50139 Firenze, Italy; elena.andreucci@meyer.it (E.A.); \\ e.lapi@meyer.it (E.L.) \\ 4 Department of Pediatrics, Clinical Genetics, Università di Padova, 35122 Padova, Italy; \\ romano.tenconi@unipd.it \\ 5 Institute of Genetics and Biophysics (IGB) "Adriano Buzzati-Traverso", Consiglio Nazionale delle \\ Ricerche (CNR), 80131 Napoli, Italy \\ * Correspondence: andrea.riccio@unicampania.it
}

check for updates

Citation: Pignata, L.; Sparago, A.; Palumbo, O.; Andreucci, E.; Lapi, E.; Tenconi, R.; Carella, M.; Riccio, A.; Cerrato, F. Mosaic Segmental and Whole-Chromosome Upd(11)mat in Silver-Russell Syndrome. Genes 2021, 12, 581. https://doi.org/10.3390/ genes12040581

Academic Editors: Miguel Constancia and Ionel Sandovici

Received: 15 March 2021

Accepted: 26 March 2021

Published: 16 April 2021

Publisher's Note: MDPI stays neutral with regard to jurisdictional claims in published maps and institutional affiliations.

Copyright: (c) 2021 by the authors. Licensee MDPI, Basel, Switzerland. This article is an open access article distributed under the terms and conditions of the Creative Commons Attribution (CC BY) license (https:/ / creativecommons.org/licenses/by/ $4.0 /)$.
Abstract: Molecular defects altering the expression of the imprinted genes of the 11p15.5 cluster are responsible for the etiology of two congenital disorders characterized by opposite growth disturbances, Silver-Russell syndrome (SRS), associated with growth restriction, and BeckwithWiedemann syndrome (BWS), associated with overgrowth. At the molecular level, SRS and BWS are characterized by defects of opposite sign, including loss (LoM) or gain (GoM) of methylation at the H19/IGF2:intergenic differentially methylated region (H19/IGF2:IG-DMR), maternal or paternal duplication (dup) of 11p15.5, maternal (mat) or paternal (pat) uniparental disomy (upd), and gain or loss of function mutations of CDKN1C. However, while upd(11)pat is found in $20 \%$ of BWS cases and in the majority of them it is segmental, upd(11)mat is extremely rare, being reported in only two SRS cases to date, and in both of them is extended to the whole chromosome. Here, we report on two novel cases of mosaic upd(11)mat with SRS phenotype. The upd is mosaic and isodisomic in both cases but covers the entire chromosome in one case and is restricted to 11p14.1-pter in the other case. The segmental upd(11)mat adds further to the list of molecular defects of opposite sign in SRS and BWS, making these two imprinting disorders even more specular than previously described.

Keywords: Silver-Russell syndrome; Beckwith-Wiedemann syndrome; genomic imprinting; imprinting disorders; uniparental disomy

\section{Introduction}

SRS (OMIM \#180860) is a congenital developmental disorder characterized by heterogeneous clinical features. Currently, the clinical diagnosis of SRS is based on the Netchine-Harbison scoring system, according to which a positive diagnosis is given in the presence of at least four out of the following clinical features: intrauterine growth restriction (IUGR), poor postnatal growth, relative macrocephaly at birth, protruding forehead, body asymmetry, and feeding difficulties. [1].

The genetics of SRS is very heterogeneous and mostly involves imprinted genes [2]. An underlying molecular cause can currently be identified in around $60 \%$ of patients with clinical diagnosis of SRS, while in the other 40\%, the molecular etiology remains unknown. The most frequent lesions are loss of methylation (LoM) of the: H19/IGF2:IG-DMR (also known as IC1) of the telomeric imprinted domain of chromosome 11p15.5 identified in 
$30-60 \%$ of the cases, followed by upd(7)mat detected in $5-10 \%$ of the cases. In a subset $(\sim 10 \%)$ of the patients with IC1 LoM, hypomethylation involves multiple imprinted loci, a condition also known as multilocus imprinting disturbances (MLID) [3,4]. Concerning the other molecular defects of 11p15.5, maternal duplications of the entire imprinted gene cluster or only the centromeric domain (including the KCNQ1OT1:Transcription Start Site-DMR, also known as KCNQ1OT1:TSS-DMR or IC2, and the CDKN1C gene) are found in less than $1 \%$ of the patients, while other $11 \mathrm{p} 15$ copy number variants (CNVs), IGF2 loss of function single nucleotide variants (SNVs), and CDKN1C gain of function SNVs are even rarer [5-7]. Mosaic upd(11)mat has been reported in only two cases to date, in both of which the whole chromosome was involved [8,9]. Molecular defects affecting further loci are generally found at a low frequency and include genetic mutations of the HMGA2 and PLAG1 genes, upd(14)mat, upd(16)mat, upd(20)mat and pathogenic CNVs at several chromosome regions [10-16].

Here, we report on two patients with mosaic upd(11)mat that is extended to the whole chromosome in one patient, and segmental and restricted to chromosome 11p14.1-pter in the other one.

\section{Material and Methods}

\subsection{Ethics}

Genetic analyses were performed after written informed consent was obtained from the patients or patients' parents. The research work was carried out in accordance with ethical principles and the Italian legislation. The study was approved by the Ethical Committee of the University of Campania "Luigi Vanvitelli" (Naples, Italy. Approval Number:1135, 13 October 2016).

\subsection{Genomic DNA Extraction}

Genomic DNA was extracted from peripheral blood leukocytes (PBL) using the saltingout procedure, and its concentration was determined using a NanoDrop spectrophotometer (Thermo Fisher Scientific, Waltham, MA, USA).

\subsection{DNA Methylation Analysis}

Methylation-specific multiple ligation-dependent probe amplification (MS-MLPA) was performed on $50 \mathrm{ng}$ of peripheral blood leukocytes (PBL) DNA to analyze DNA methylation and CNVs of several imprinted DMRs by using the SALSA MS-MLPA Kit ME034-B1 (MRC-Holland, Amsterdam, The Netherlands). The amplified products were separated by capillary electrophoresis using an ABI 3500 Genetic Analyzer (Applied Biosystems, Foster City, CA, USA). Data were analyzed using Coffalyser software (MRC-Holland, Amsterdam, The Netherlands).

For the combined bisulfite restriction assay (COBRA), $2 \mu \mathrm{g}$ of PBL DNA was treated with sodium bisulfite using the EpiTect Bisulfite kit (Qiagen-Italia, Milan, Italy) following the manufacturer's instructions. Bisulfite-treated DNA was amplified with primers targeting regions within IC1 and IC2. The PCR products were then digested with BstUI (CGCG). Digested (methylated) and undigested (non-methylated) bands were separeted after electrophoresis on a polyacrylamide gel and quantified by phosphorimager to calculate the percentage of methylation. Primer sequences, PCR, and restriction enzyme reaction conditions were previously described $[17,18]$.

Pyrosequencing analysis was carried out as previously reported [19].

\subsection{SNP Array}

Whole-genome CNVs analysis was carried out as previously reported in [20]. The calculation of the mosaic ratio was based on the intensity and distribution of each single nucleotide polymorphism (SNP) allele present on chromosome 11 considering the arbitrary fluorescence unit of haploid locus (single allele) $=0.5$ [21]. In the allele difference track, each point represents a SNP interrogated by " $\mathrm{A}$ " + " $\mathrm{B}$ " allele probes. In physiological conditions, 
the genotype can be "AA" $=[0.5+0.5]-[0]=1$, genotype " $\mathrm{AB}^{\prime}=[0.5]-[0.5]=0$, genotype "BB" $=[0]-[0.5+0.5]=-1$. Analysis of the allelic differentiation reveals copy neutral mosaicism found in upd as tracts diverging from the common midpoint heterozygote 0 line. Complete chromosome upd is characterized by the absence of a heterozygous state. Mosaic upd is characterized by the presence of lines for AA (intensity $=1$ ) and BB (intensity $=-1$ ), the absence of $A B$, and two new profiles representative of mosaic genotypes $A A / A B$ and $\mathrm{AB} / \mathrm{BB}$, The mix of $\mathrm{AB}$ (germline) alleles with converted AA or BB alleles at each SNP generates novel mosaic tracts that represent the relative percentage of upd.

\subsection{Microsatellite Analysis}

Three microsatellites, TH, D11S4088, and D11S922, of chromosome 11p were evaluated in patients and their parents. Primer sequences and PCR condition were obtained from the NCBI Genome Database. PCR amplification of $100 \mathrm{ng}$ DNA was conducted using a forward primer end labeled with Fam or Hex. PCR products were run on the fluorescent capillary system ABI 3500. Data were analyzed using GeneMapper Software (version 5).

\section{Results}

\subsection{Clinical Cases}

The two patients described in this study were referred to our laboratory with a clinical diagnosis of SRS based on the Netchine-Harbison clinical scoring system [1]. The proband of family 1 (II-1 in the pedigree of family 1 in Figure 1) was a 17-year-old boy born after 34 weeks of gestation from healthy unrelated parents. During pregnancy, IUGR and oligohydramnios were reported. Birth weight was $1050 \mathrm{~g}$ ( $<3$ rd centile), birth length 36 $\mathrm{cm}(<3$ rd centile), and head circumference $30 \mathrm{~cm}$ (25th centile). At birth, he presented feeding difficulties and respiratory distress. During the postnatal period, feeding difficulties persisted, worsened by the presence of gastro-esophageal reflux. Clinical examination at 1 year revealed skeletal body asymmetry (right part $>$ left part), a small and triangular face with protruding forehead, micrognathia, thin lips, ear abnormalities, fifth finger brachydactyly and clinodactyly, muscular hypotonia, and psychomotor and speech delays. Growth hormone (GH) therapy was undertaken at 6 years because of documented GH deficiency. Chromosome analysis was also performed, revealing a normal 46, XY karyotype. The parents showed no feature of SRS.

The proband of family 2 (II- 1 in the pedigree of family 2 in Figure 1) was a 21-year-old man born from non-consanguineous parents. During pregnancy, IUGR was detected. The fetal umbilical blood sampling showed a 46, XY karyotype in 30 metaphases analyzed (G-banding, 300-400 bands). He was born after 35 weeks of gestation, with a birth weight of $1585 \mathrm{~g}$ ( $<3$ rd centile), length of $38 \mathrm{~cm}$ ( $<3$ rd centile) and cranial circumference of $31.1 \mathrm{~cm}$ (10-25th centile). During the perinatal period, he displayed psychomotor delay and severe feeding difficulties, which persisted during the postnatal period. Hypoglycemia and exceeding sweating occurred in the first year of life. Clinical examination at 6 years revealed skeletal body asymmetry (superior and inferior limbs), a small and triangular face with a protruding forehead, thin lips, ear anomalies, arched palate, cryptorchidism, muscular hypotonia, and motor delay. He is currently attending the second year of university, but he presents motor problems and asthenia. He was treated with GH therapy for about 8 years. No clinical signs of SRS were reported in the parents. 

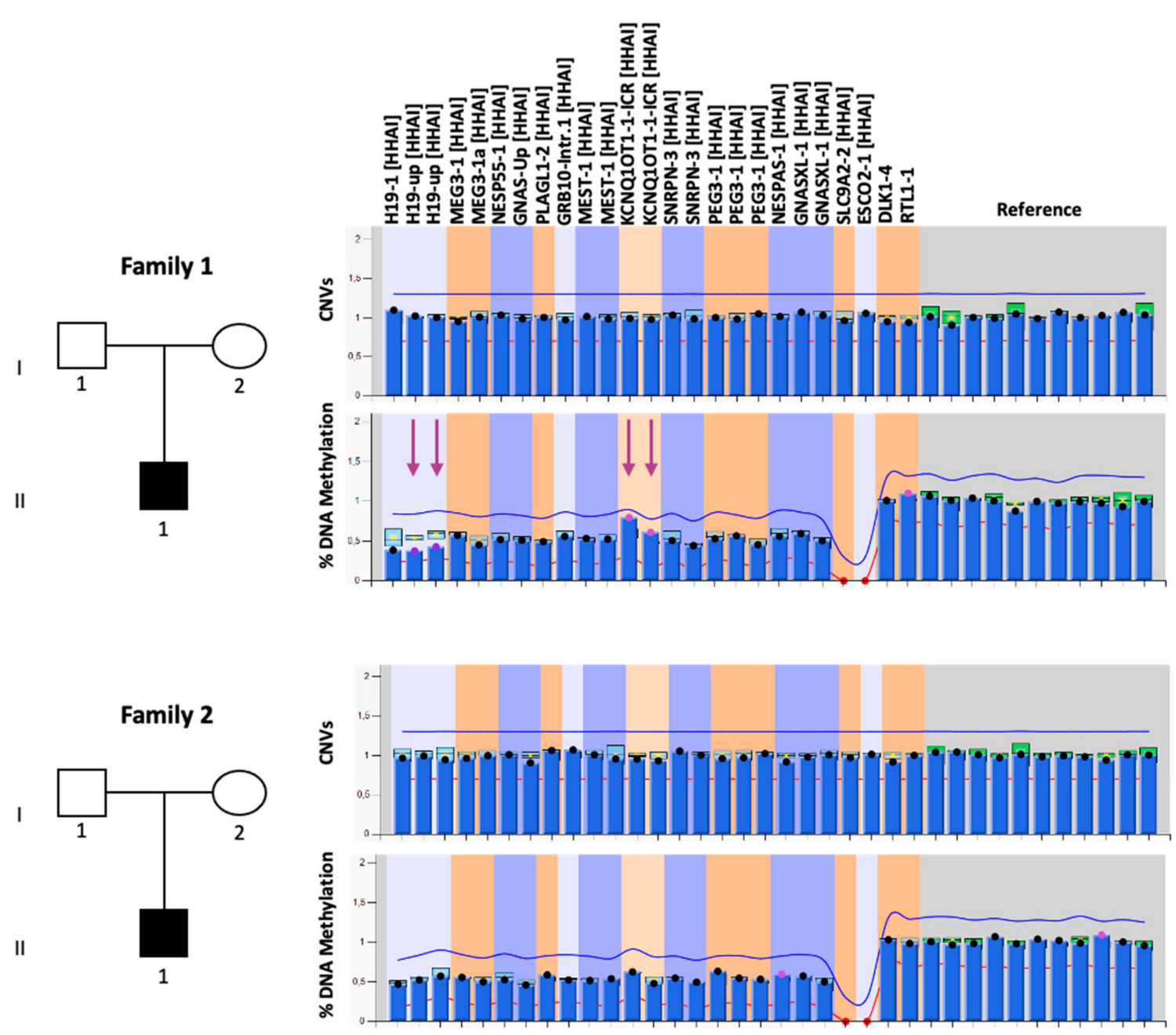

Figure 1. Genetic characterization of the probands and their families. Left: pedigrees of the two families. Right: MS-MLPA results. CNVs (upper panels) and DNA methylation (lower panels) were analyzed at 10 imprinted loci, reported at the top of the figure. The mean values of seven control subjects were utilized for the assessment of relative copy number and methylation percentage. The purple arrows indicate the affected regions.

\subsection{Molecular Diagnosis}

Molecular testing for SRS was performed by MS-MLPA on DNA extracted from PBL of the probands, their parents, and unaffected individuals used as controls. In order to test the majority of the molecular defects of SRS through a single approach, we employed the SALSA MS-MLPA Kit ME034-B1 (MRC-Holland, Amsterdam, The Netherlands), which allows one to determine CNVs and DNA methylation of several imprinted loci (H19, KCNQ1OT1, PLAGL1, GRB10, MEST, DLK1/MEG3, SNRPN, PEG3, and GNAS/NESPAS). The analysis of copy number did not reveal any CNVs in either of the two probands (Figure 1). The methylation analysis performed by MS-MLPA revealed IC1 LoM and IC2 GoM at $11 \mathrm{p} 15.5$ in the proband 1 ( $41 \%$ and $71 \%$, respectively), while methylation levels comparable to seven unaffected control subjects were detected at these DMRs in the proband 2. Normal methylation levels were found at the other DMRs, thereby excluding MLID in both patients (Figure 1).

To exclude the possibility that methylation abnormalities were undetected in proband 2 because of the relatively low sensitivity of the MS-MLPA, we tested his DNA by using another technique, the COBRA. By employing this method, a slight IC1 LoM and a slight IC2 GoM were found in the proband 2 DNA compared to that of his parents and two controls (Figure S1). No CNVs and normal methylation levels of the analyzed regions were found in the parents of both probands (Table S1). The slight methylation defect 
of the two 11p15.5 DMRs was further confirmed in both the probands by using a third approach, the bisulfite treatment of DNA followed by pyrosequencing (Figure 2 and Table S2), which was performed to analyze, in addition to IC1 and IC2, MEST:alt-TSS-DMR and GRB10:alt-TSS-DMR as controls.

H19/IGF2:IG-DMR

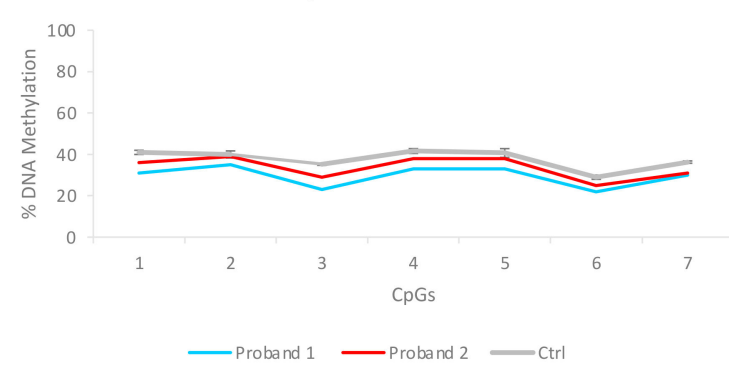

MEST:alt-TSS-DMR

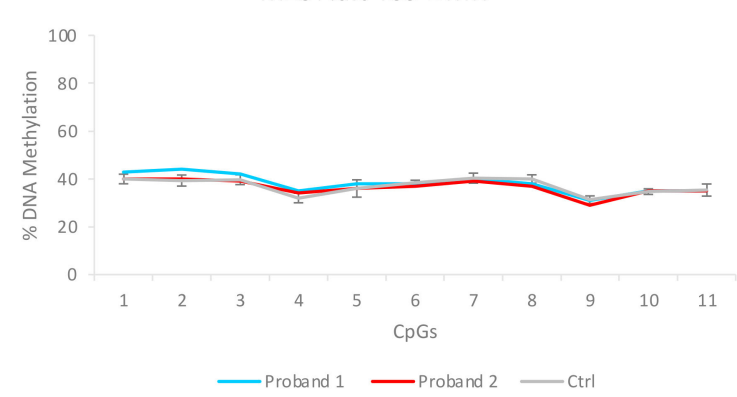

KCNQ1OT1:TSS-DMR

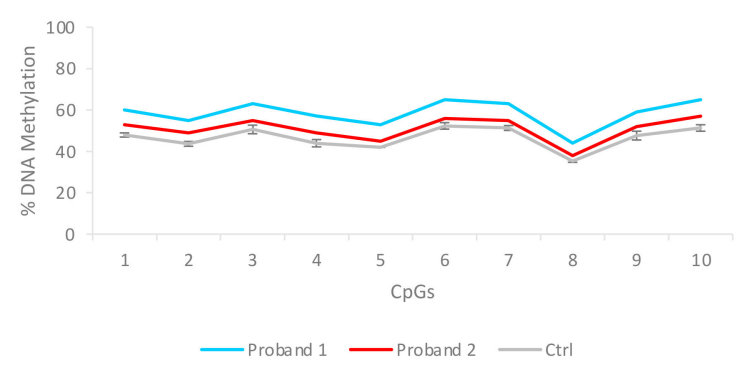

GRB10:alt-TSS-DMR

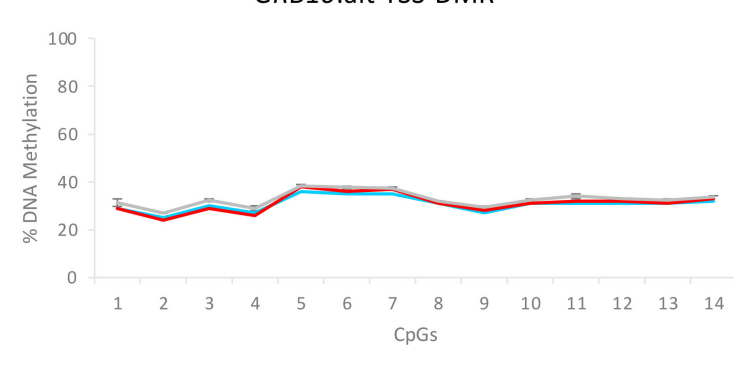

Figure 2. DNA methylation analysis of four DMRs performed on proband 1 and proband 2. Ctrl: average of three unaffected individuals.

In summary, the opposite methylation defects of the 11p15.5 DMRs without evidence of CNVs suggest the presence of maternal upd in both proband 1 and proband 2.

\subsection{Characterization of the Molecular Defects}

To better characterize the molecular defects of the probands, we further analyzed their PBL DNA by employing the SNP array. Mosaic upd(11)mat was identified in the probands 1 and 2 (Figure 3). Interestingly, in proband 1, upd was segmental and restricted to chromosome region 11p14.1-pter, while in proband 2 the upd was extended to the whole chromosome 11 . The percentage of mosaicism was $20 \%$ in the proband 1 and $\sim 10-15 \%$ in the proband 2. No upd pathogenic CNVs were identified in proband 1's parents by SNP array analysis (Figure S2). The parents of proband 2 could not be analyzed because the required DNA was unavailable. The analysis of three informative short tandem repeats (STR) markers (D11S922, TH, D11S4088) indicated the presence of maternal uniparental isodisomy (UPiD) of chromosome 11p15.5 in both probands 1 and 2 and excluded the heterodisomy (Table 1). 


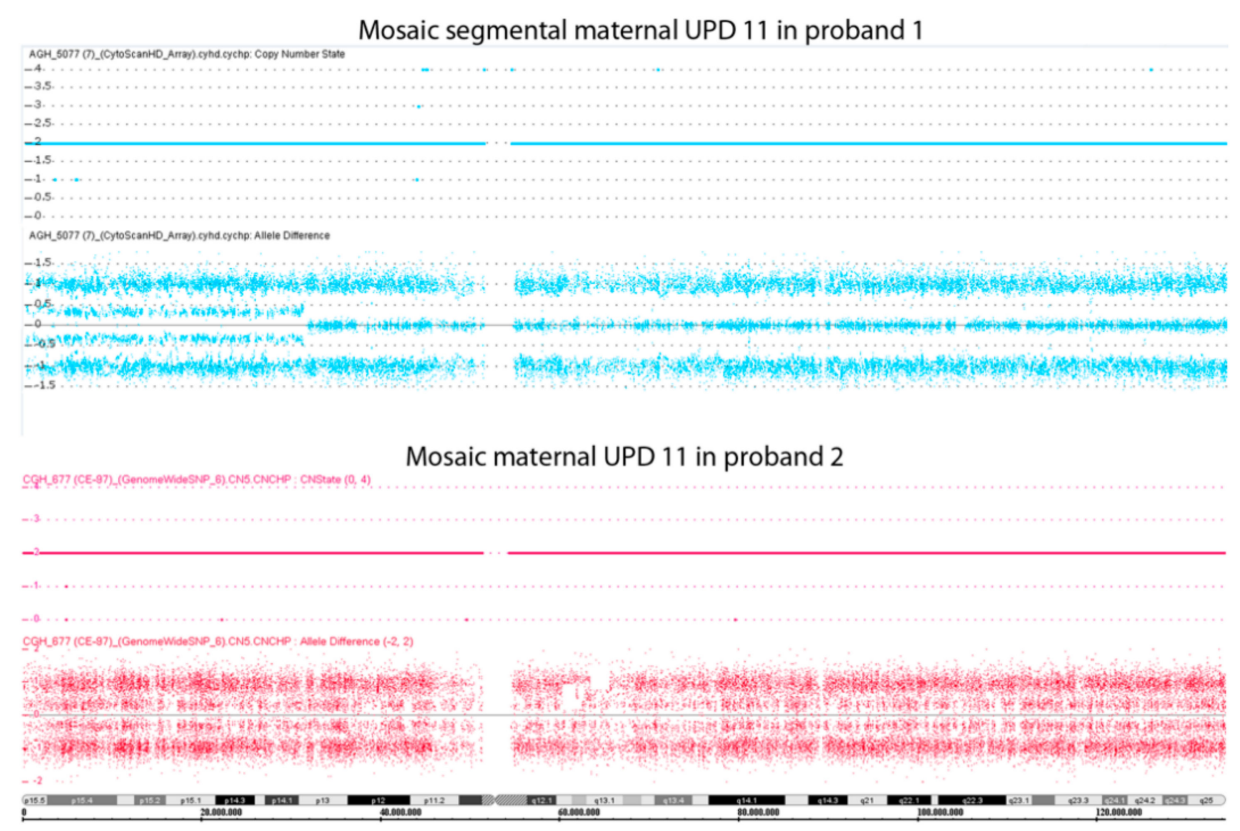

Figure 3. SNP array analysis on genomic DNA of the two probands. Each panel represents the SNP array results of chromosome 11 only. The upper graphs indicate the copy number state; the lower graphs indicate the B allele frequency for each SNP. Note the differences presented by these two cases on the extent of upd, partial in proband 1 and complete in proband 2, and their level of mosaicism, which is higher for proband 1 (20\%) than for proband $2(\sim 10-15 \%)$.

Table 1. Summary of genotypes of probands with mosaic upd 11 and their parents for three short tandem repeats (STRs) on chromosome 11p15.5.

\begin{tabular}{ccl}
\hline STR & Family 1 & Family 2 \\
\hline D11S922 & $\mathrm{bc}^{*}, \mathrm{ac}, \mathrm{bd}$ & $\mathrm{aa}, \mathrm{ab}, \mathrm{ab}$ \\
\hline TH & $\mathrm{a}^{*} \mathrm{c}, \mathrm{ab}, \mathrm{cd}$ & $\mathrm{b}^{*} \mathrm{c}, \mathrm{ab}, \mathrm{cc}$ \\
\hline D11S4088 & $\mathrm{a}^{*} \mathrm{c}, \mathrm{ab}, \mathrm{cd}$ & $\mathrm{c}^{*} \mathrm{~d}, \mathrm{ac}, \mathrm{bd}$ \\
\hline
\end{tabular}

The alleles are given in the following order: patient, mother, father. Allele designations (marked a to d) are arbitrary. The asterisk indicates the allele with higher intensity in the probands.

\section{Discussion}

Lesions at the 11p15 imprinted gene cluster represent the majority of molecular defects associated with SRS to date. They include the frequent IC1 hypomethylation, the rare CNVs, and the extremely rare upd(11)mat and IGF2 and CDKN1C mutations. We have identified two novel cases with mosaic maternal UPiD 11 and the typical SRS phenotype. In one of the patients, the maternal UPiD 11 is restricted to 11p14.1-pter and represents the first reported case of such molecular defect in SRS.

The segmental upd(11) mat adds further to the list of molecular defects of opposite sign in SRS and BWS, making these two imprinting disorders even more specular than previously described. However, some differences are worth mentioning. Mosaic upd(11)pat is a frequent molecular defect in BWS affecting $20 \%$ of the cases [22], most of which $(78-92 \%)$ are reported to have a segmental upd 11p [23,24]. Conversely, mosaic upd(11)mat is extremely rare in SRS, and of the four cases reported to date, three of them have wholechromosome upd(11)mat.

Upd can arise as meiotic or mitotic errors [25,26]. In our probands, somatic mosaicism and isodisomy suggest post-fertilization errors that might derive from mitotic nondisjunction followed by trisomic rescue in the case of complete upd or mitotic recombination between non-sister chromatids in the case of segmental upd. The latter is assumed to be the most probable event causing mosaic segmental paternal UPiD 11 in BWS. It should result 
in the formation of two daughter cells, one with maternal isodisomy and the other one with paternal isodisomy. The cells with upd(11)pat are expected to have a selective advantage over the upd(11)mat because of the altered dosage of imprinted genes controlling cell growth (including IGF2, H19, and CDKN1C) [26,27]. The finding of segmental upd(11)mat may be explained by the presence of a recessive mutation on the paternal chromosome, resulting in the negative selection of the cells with paternal isodisomy. Alternatively, other somatic recombination events similar to gene conversion might be responsible for the formation of segmental maternal UPiD 11 [28].

The mosaic whole-chromosome UPiD 11 of both SRS and BWS is likely derived from mitotic nondisjunction followed by trisomic rescue. Indeed, loss of one of the supernumerary chromosomes is a prerequisite for the survival of trisomic embryos. In one-third of these cases, the homolog that is present in single copy is lost, thus giving rise to a upd [25]. It is plausible that the chromosome that is lost is the maternal or paternal one by chance, determining mosaic complete maternal or paternal UPiD 11 with the same probability. Consistent with this hypothesis, this defect is similarly rare in SRS and BWS $[8,9,23,24]$.

Upd 11 has been reported in a mosaic form only to date, suggesting that the nonmosaic form is incompatible with life, because an altered dosage of the 11p15 imprinted genes is tolerated only if restricted to a subset of somatic cells [26,29]. Similar to the previously reported cases of upd(11)mat, the percentage of mosaicism in our patients is very low $(10-20 \%)[8,9]$ and generally lower than that reported in BWS cases [23,24]. This suggests that differently from upd(11)pat, upd(11)mat is compatible with life only if it affects a very restricted number of cells. For this reason, it may be that mosaic upd(11)mat is a more common cause of SRS than was currently observed, since it is difficult to detect, either for technical reasons or because it involves tissues other than the leukocytes sampled for testing [9].

At the clinical level, apart from the micrognathia and down-turned mouth, no main difference can be found between the case with segmental and those with whole-chromosome upd(11)mat (present case and those reported in [8,9]) (Table 2). No major phenotypic difference has been reported also between segmental and whole-chromosome upd(11)pat in BWS; thus, it has been proposed that, rather than the extension of the upd, the proportion of the cells and the kind of tissues affected is responsible for the variability of the clinical manifestations [24,30,31]. Concerning the SRS molecular subgroups, the main phenotypic difference is body asymmetry (Table 2). Body asymmetry is present in the patients described in the present study and the other reported mosaic upd(11)mat as well as in $77 \%$ IC1 LoM cases, but only in $29 \%$ upd(7)mat cases, and it is generally absent in $11 \mathrm{p} 15$ duplication cases. These differences are likely due to mosaicism that is always associated with upd 11, frequently associated with IC1 LoM, and usually absent in upd(7)mat and $11 \mathrm{p} 15$ duplication cases. No further clinical feature appears to be significantly different in its frequency between the upd(11)mat and the other SRS molecular subgroups.

Table 2. Frequency of clinical features in the main SRS molecular subgroups.

\begin{tabular}{|c|c|c|c|c|c|c|c|}
\hline Clinical Sign & $\begin{array}{c}\text { Proband 1 } \\
\text { (Segmental) }\end{array}$ & $\begin{array}{c}\text { Proband } 2 \\
\text { (Whole- } \\
\text { Chromosome) }\end{array}$ & $\begin{array}{c}\text { Proband } \\
\text { Described in } \\
\text { [8] (Whole- } \\
\text { Chromosome) }\end{array}$ & $\begin{array}{c}\text { Proband } \\
\text { Described in } \\
\text { [9] (Whole- } \\
\text { Chromosome) }\end{array}$ & $\begin{array}{l}\text { 11p15 LoM } \\
(\%) *\end{array}$ & Upd(7)mat (\%) * & 11 p15 dup (\%) \\
\hline Sex & Male & Male & Female & Male & & & \\
\hline $\begin{array}{l}1 \text { SGA: birth } \\
\text { weight and/or } \\
\text { birth length }\end{array}$ & Yes & Yes & Yes & Yes & 100 & 73 & $100 * *$ \\
\hline $\begin{array}{l}\text { Postnatal } \\
\text { growth failure }\end{array}$ & Yes & Yes & Yes & Yes & 84 & 81 & $100 * *$ \\
\hline $\begin{array}{c}\text { Relative } \\
\text { macrocephaly } \\
\text { at birth }\end{array}$ & Yes & Yes & No & Yes & 99 & 85 & $95^{* *}$ \\
\hline
\end{tabular}


Table 2. Cont.

\begin{tabular}{|c|c|c|c|c|c|c|c|}
\hline Clinical Sign & $\begin{array}{c}\text { Proband 1 } \\
\text { (Segmental) }\end{array}$ & $\begin{array}{c}\text { Proband } 2 \\
\text { (Whole- } \\
\text { Chromosome) }\end{array}$ & $\begin{array}{c}\text { Proband } \\
\text { Described in } \\
\text { [8] (Whole- } \\
\text { Chromosome) }\end{array}$ & $\begin{array}{c}\text { Proband } \\
\text { Described in } \\
\text { [9] (Whole- } \\
\text { Chromosome) }\end{array}$ & $\begin{array}{c}\text { 11p15 LoM } \\
(\%)^{*}\end{array}$ & $\operatorname{Upd}(7) \operatorname{mat}(\%) *$ & 11 p15 dup (\%) \\
\hline $\begin{array}{l}\text { Protruding } \\
\text { forehead }\end{array}$ & Yes & Yes & Yes & Yes & 94 & 100 & $90 * *$ \\
\hline $\begin{array}{c}\text { Body } \\
\text { asymmetry }\end{array}$ & Yes & Yes & Yes & Yes & 77 & 29 & $0 * *$ \\
\hline $\begin{array}{c}\text { Feeding } \\
\text { difficulties } \\
\text { and/or low } \\
\text { BMI }\end{array}$ & Yes & Yes & Yes & Yes & 72 & 87 & $88^{* *}$ \\
\hline Triangular face & Yes & Yes & Yes & Yes & 99 & 50 & $74^{* * *}$ \\
\hline $\begin{array}{l}\text { Fifth finger } \\
\text { clinodactyly }\end{array}$ & Yes & No & Yes & Yes & 81 & 56 & $93 * * *$ \\
\hline Micrognathia & Yes & No & No & No & 75 & 26 & $\mathrm{nr} * * *$ \\
\hline $\begin{array}{l}\text { Low muscle } \\
\text { mass }\end{array}$ & Yes & Yes & No & No & 67 & 47 & $67^{* * *}$ \\
\hline $\begin{array}{l}\text { Excessive } \\
\text { sweating }\end{array}$ & No & Yes & Yes & No & 51 & 70 & $\mathrm{nr} * * *$ \\
\hline $\begin{array}{l}\text { Down-turned } \\
\text { mouth }\end{array}$ & Yes & No & No & No & 57 & 26 & $\mathrm{nr} * * *$ \\
\hline $\begin{array}{c}\text { Genital } \\
\text { abnormalities }\end{array}$ & No & Yes & No & Yes & $\mathrm{nr}$ & $\mathrm{nr}$ & $\mathrm{nr} * * *$ \\
\hline Speech delay & Yes & No & No & Yes & 32 & 64 & \multirow{2}{*}{$78^{* * *}$} \\
\hline Motor delay & Yes & Yes & Yes & No & 30 & 58 & \\
\hline
\end{tabular}

${ }^{1}$ SGA: small for gestational age; BMI: body mass index; the extension of the upd in each proband is reported in brackets. Cases reported in ${ }^{*}[2],{ }^{* *}[32-34], * * *[33,34]$.

\section{Conclusions}

In conclusion, we reported on two novel SRS cases with the extremely rare mosaic upd(11)mat. In one of these cases, upd(11)mat is extended to the whole chromosome and in the other is restricted to 11p14.1-pter. Such finding increases the list of molecular defects of opposite sign in SRS and BWS, although in BWS upd(11)pat is relatively common and generally segmental, while in SRS upd(11)mat is rare and more frequently affecting the entire chromosome. The rare case of mosaic segmental upd(11)mat in SRS is likely caused by mitotic recombination associated with the presence of a recessive mutation on the paternal chromosome resulting in the negative selection of the upd(11)pat cells.

Supplementary Materials: The following are available online at https:/ / www.mdpi.com/article/10 .3390/genes12040581/s1, Figure S1: SNP array analysis on genomic DNA of the parents of proband 1. Figure S1: DNA methylation analysis of the 11p15.5 DMRs obtained on the TRIO of family 2 by COBRA, Figure S2: SNP array analysis on genomic DNA of the parents of proband 1, Table S1: Copy number and DNA methylation values of several imprinted loci obtained by MS-MLPA, Table S2: DNA methylation values of four imprinted DMRs obtained by pyrosequencing.

Author Contributions: Conceptualization, L.P., F.C. and A.R.; formal analysis and investigation, L.P., A.S., O.P. and M.C.; resources, E.A., E.L. and R.T.; data curation, L.P., A.S., L.P., O.P. and M.C.; writing-original draft preparation, review and editing, L.P., F.C. and A.R.; supervision, A.R.; funding acquisition, A.R., F.C. and A.S. All authors have read and agreed to the published version of the manuscript.

Funding: This research was funded by the followings grants: AIRC-Associazione Italiana Ricerca sul Cancro IG 2020 ID 24405 (A.R.), Telethon-Italia GGP15131 (A.R.), "Progetti per la ricerca oncologica della Regione Campania" Grant: I-Cure (A.R. and F.C.), "Progetti competitivi intraAteneo" Programma V:ALERE (VAnviteLli pEr la RicErca) 2019—grant MIRIAM from Università degli Studi della Campania "Luigi Vanvitelli" (A.R., F.C. and A.S.). 
Institutional Review Board Statement: The study was conducted according to the guidelines of the Declaration of Helsinki and approved by the Ethics Committee of the University of Campania "Luigi Vanvitelli", Naples, Italy (protocol code 1135, 13 October 2016).

Informed Consent Statement: Informed consent was obtained from all subjects involved in the study.

Acknowledgments: The authors are grateful to the patients and their parents.

Conflicts of Interest: The authors declare no conflict of interest. The funders had no role in the design of the study; in the collection, analyses, or interpretation of data; in the writing of the manuscript; or in the decision to publish the results.

\section{References}

1. Azzi, S.; Salem, J.; Thibaud, N.; Chantot-Bastaraud, S.; Lieber, E.; Netchine, I.; Harbison, M.D. A prospective study validating a clinical scoring system and demonstrating phenotypical-genotypical correlations in Silver-Russell syndrome. J. Med. Genet. 2015, 52, 446-453. [CrossRef] [PubMed]

2. Wakeling, E.L.; Brioude, F.; Lokulo-Sodipe, O.; O'Connell, S.M.; Salem, J.; Bliek, J.; Canton, A.P.; Chrzanowska, K.H.; Davies, J.H.; Dias, R.P.; et al. Diagnosis and management of Silver-Russell syndrome: First international consensus statement. Nat. Rev. Endocrinol. 2017, 13, 105-124. [CrossRef] [PubMed]

3. Soellner, L.; Kraft, F.; Sauer, S.; Begemann, M.; Kurth, I.; Elbracht, M.; Eggermann, T. Search for cis-acting factors and maternal effect variants in Silver-Russell patients with ICR1 hypomethylation and their mothers. Eur. J. Hum. Genet. 2019, $27,42-48$. [CrossRef] [PubMed]

4. Azzi, S.; Rossignol, S.; Steunou, V.; Sas, T.; Thibaud, N.; Danton, F.; Le Jule, M.; Heinrichs, C.; Cabrol, S.; Gicquel, C.; et al. Multilocus methylation analysis in a large cohort of 11p15-related foetal growth disorders (Russell Silver and Beckwith Wiedemann syndromes) reveals simultaneous loss of methylation at paternal and maternal imprinted loci. Hum. Mol. Genet. 2009, 18, 4724-4733. [CrossRef] [PubMed]

5. Brioude, F.; Oliver-Petit, I.; Blaise, A.; Praz, F.; Rossignol, S.; Le Jule, M.; Thibaud, N.; Faussat, A.M.; Tauber, M.; Le Bouc, Y.; et al. CDKN1C mutation affecting the PCNA-binding domain as a cause of familial Russell Silver syndrome. J. Med. Genet. 2013, 50, 823-830. [CrossRef]

6. Mio, C.; Allegri, L.; Passon, N.; Bregant, E.; Demori, E.; Franzoni, A.; Driul, D.; Riccio, A.; Damante, G.; Baldan, F. A paternally inherited $1.4 \mathrm{~kb}$ deletion of the $11 \mathrm{p} 15.5$ imprinting center 2 is associated with a mild familial Silver-Russell syndrome phenotype. Eur. J. Hum. Genet. 2021, 29, 447-454. [CrossRef]

7. Begemann, M.; Zirn, B.; Santen, G.; Wirthgen, E.; Soellner, L.; Büttel, H.M.; Schweizer, R.; van Workum, W.; Binder, G.; Eggermann, T. Paternally Inherited IGF2 Mutation and Growth Restriction. N. Engl. J. Med. 2015, 373, 349-356. [CrossRef]

8. Bullman, H.; Lever, M.; Robinson, D.O.; Mackay, D.J.; Holder, S.E.; Wakeling, E.L. Mosaic maternal uniparental disomy of chromosome 11 in a patient with Silver-Russell syndrome. J. Med. Genet. 2008, 45, 396-399. [CrossRef] [PubMed]

9. Luk, H.M.; Ivan Lo, F.M.; Sano, S.; Matsubara, K.; Nakamura, A.; Ogata, T.; Kagami, M. Silver-Russell syndrome in a patient with somatic mosaicism for upd(11)mat identified by buccal cell analysis. Am. J. Med. Genet. A 2016, 170, 1938-1941. [CrossRef] [PubMed]

10. De Crescenzo, A.; Citro, V.; Freschi, A.; Sparago, A.; Palumbo, O.; Cubellis, M.V.; Carella, M.; Castelluccio, P.; Cavaliere, M.L.; Cerrato, F.; et al. A splicing mutation of the HMGA2 gene is associated with Silver-Russell syndrome phenotype. J. Hum. Genet. 2015, 60, 287-293. [CrossRef] [PubMed]

11. Abi Habib, W.; Brioude, F.; Edouard, T.; Bennett, J.T.; Lienhardt-Roussie, A.; Tixier, F.; Salem, J.; Yuen, T.; Azzi, S.; Le Bouc, Y.; et al. Genetic disruption of the oncogenic HMGA2-PLAG1-IGF2 pathway causes fetal growth restriction. Genet. Med. 2018, 20, 250-258. [CrossRef]

12. Poole, R.L.; Docherty, L.E.; Al Sayegh, A.; Caliebe, A.; Turner, C.; Baple, E.; Wakeling, E.; Harrison, L.; Lehmann, A.; Temple, I.K.; et al. Targeted methylation testing of a patient cohort broadens the epigenetic and clinical description of imprinting disorders. Am. J. Med. Genet. A 2013, 161A, 2174-2182. [CrossRef] [PubMed]

13. Kagami, M.; Mizuno, S.; Matsubara, K.; Nakabayashi, K.; Sano, S.; Fuke, T.; Fukami, M.; Ogata, T. Epimutations of the IG-DMR and the MEG3-DMR at the 14q32.2 imprinted region in two patients with Silver-Russell Syndrome-compatible phenotype. Eur. J. Hum. Genet. 2015, 23, 1062-1067. [CrossRef]

14. Hjortshøj, T.D.; Sørensen, A.R.; Yusibova, M.; Hansen, B.M.; Dunø, M.; Balslev-Harder, M.; Grønskov, K.; van Hagen, J.M.; Polstra, A.M.; Eggermann, T.; et al. upd(20)mat is a rare cause of the Silver-Russell-syndrome-like phenotype: Two unrelated cases and screening of large cohorts. Clin. Genet. 2020, 97, 902-907. [CrossRef]

15. Inoue, T.; Yagasaki, H.; Nishioka, J.; Nakamura, A.; Matsubara, K.; Narumi, S.; Nakabayashi, K.; Yamazawa, K.; Fuke, T.; Oka, A.; et al. Molecular and clinical analyses of two patients with UPD(16)mat detected by screening 94 patients with SilverRussell syndrome phenotype of unknown aetiology. J. Med. Genet. 2019, 56, 413-418. [CrossRef] [PubMed]

16. Inoue, T.; Nakamura, A.; Iwahashi-Odano, M.; Tanase-Nakao, K.; Matsubara, K.; Nishioka, J.; Maruo, Y.; Hasegawa, Y.; Suzumura, H.; Sato, S.; et al. Contribution of gene mutations to Silver-Russell syndrome phenotype: Multigene sequencing analysis in 92 etiology-unknown patients. Clin. Epigenetics 2020, 12, 86. [CrossRef] [PubMed] 
17. Bliek, J.; Verde, G.; Callaway, J.; Maas, S.M.; De Crescenzo, A.; Sparago, A.; Cerrato, F.; Russo, S.; Ferraiuolo, S.; Rinaldi, M.M.; et al. Hypomethylation at multiple maternally methylated imprinted regions including PLAGL1 and GNAS loci in BeckwithWiedemann syndrome. Eur. J. Hum. Genet. 2009, 17, 611-619. [CrossRef]

18. Bourque, D.K.; Avila, L.; Peñaherrera, M.; von Dadelszen, P.; Robinson, W.P. Decreased placental methylation at the H19/IGF2 imprinting control region is associated with normotensive intrauterine growth restriction but not preeclampsia. Placenta 2010, 31, 197-202. [CrossRef] [PubMed]

19. Cubellis, M.V.; Pignata, L.; Verma, A.; Sparago, A.; Del Prete, R.; Monticelli, M.; Calzari, L.; Antona, V.; Melis, D.; Tenconi, R.; et al. Loss-of-function maternal-effect mutations of PADI6 are associated with familial and sporadic Beckwith-Wiedemann syndrome with multi-locus imprinting disturbance. Clin. Epigenetics 2020, 12, 139. [CrossRef]

20. Palumbo, O.; Fichera, M.; Palumbo, P.; Rizzo, R.; Mazzolla, E.; Cocuzza, D.M.; Carella, M.; Mattina, T. TBR1 is the candidate gene for intellectual disability in patients with a 2q24.2 interstitial deletion. Am. J. Med. Genet. A 2014, 164A, 828-833. [CrossRef] [PubMed]

21. Papenhausen, P.; Schwartz, S.; Risheg, H.; Keitges, E.; Gadi, I.; Burnside, R.D.; Jaswaney, V.; Pappas, J.; Pasion, R.; Friedman, K.; et al. UPD detection using homozygosity profiling with a SNP genotyping microarray. Am. J. Med. Genet. A 2011, 155A, 757-768. [CrossRef]

22. Brioude, F.; Kalish, J.M.; Mussa, A.; Foster, A.C.; Bliek, J.; Ferrero, G.B.; Boonen, S.E.; Cole, T.; Baker, R.; Bertoletti, M.; et al. Expert consensus document: Clinical and molecular diagnosis, screening and management of Beckwith-Wiedemann syndrome: An international consensus statement. Nat. Rev. Endocrinol. 2018, 14, 229-249. [CrossRef]

23. Cooper, W.N.; Curley, R.; Macdonald, F.; Maher, E.R. Mitotic recombination and uniparental disomy in Beckwith-Wiedemann syndrome. Genomics 2007, 89, 613-617. [CrossRef] [PubMed]

24. Ohtsuka, Y.; Higashimoto, K.; Oka, T.; Yatsuki, H.; Jozaki, K.; Maeda, T.; Kawahara, K.; Hamasaki, Y.; Matsuo, M.; Nishioka, K.; et al. Identification of consensus motifs associated with mitotic recombination and clinical characteristics in patients with paternal uniparental isodisomy of chromosome 11. Hum. Mol. Genet. 2016, 25, 1406-1419. [CrossRef] [PubMed]

25. Eggermann, T. Prenatal Detection of Uniparental Disomies (UPD): Intended and Incidental Finding in the Era of Next Generation Genomics. Genes (Basel) 2020, 11, 1454. [CrossRef] [PubMed]

26. Kotzot, D. Complex and segmental uniparental disomy (UPD): Review and lessons from rare chromosomal complements. J. Med. Genet. 2001, 38, 497-507. [CrossRef] [PubMed]

27. Bischoff, F.Z.; Feldman, G.L.; McCaskill, C.; Subramanian, S.; Hughes, M.R.; Shaffer, L.G. Single cell analysis demonstrating somatic mosaicism involving $11 \mathrm{p}$ in a patient with paternal isodisomy and Beckwith-Wiedemann syndrome. Hum. Mol. Genet. 1995, 4, 395-399. [CrossRef]

28. Bonaglia, M.C.; Giorda, R.; Beri, S.; Bigoni, S.; Sensi, A.; Baroncini, A.; Capucci, A.; De Agostini, C.; Gwilliam, R.; Deloukas, P.; et al. Mosaic 22q13 deletions: Evidence for concurrent mosaic segmental isodisomy and gene conversion. Eur. J. Hum. Genet. 2009, 17, 426-433. [CrossRef]

29. Reik, W.; Brown, K.W.; Slatter, R.E.; Sartori, P.; Elliott, M.; Maher, E.R. Allelic methylation of H19 and IGF2 in the BeckwithWiedemann syndrome. Hum. Mol. Genet. 1994, 3, 1297-1301. [CrossRef]

30. Dutly, F.; Baumer, A.; Kayserili, H.; Yüksel-Apak, M.; Zerova, T.; Hebisch, G.; Schinzel, A. Seven cases of Wiedmann-Beckwith syndrome, including the first reported case of mosaic paternal isodisomy along the whole chromosome 11. Am. J. Med. Genet. 1998, 79, 347-353. [CrossRef]

31. Romanelli, V.; Meneses, H.N.; Fernández, L.; Martínez-Glez, V.; Gracia-Bouthelier, R.; F Fraga, M.; Guillén, E.; Nevado, J.; Gean, E.; Martorell, L.; et al. Beckwith-Wiedemann syndrome and uniparental disomy 11p: Fine mapping of the recombination breakpoints and evaluation of several techniques. Eur. J. Hum. Genet. 2011, 19, 416-421. [CrossRef]

32. Heide, S.; Chantot-Bastaraud, S.; Keren, B.; Harbison, M.D.; Azzi, S.; Rossignol, S.; Michot, C.; Lackmy-Port Lys, M.; Demeer, B.; Heinrichs, C.; et al. Chromosomal rearrangements in the 11p15 imprinted region: 17 new 11p15.5 duplications with associated phenotypes and putative functional consequences. J. Med. Genet. 2018, 55, 205-213. [CrossRef]

33. Chiesa, N.; De Crescenzo, A.; Mishra, K.; Perone, L.; Carella, M.; Palumbo, O.; Mussa, A.; Sparago, A.; Cerrato, F.; Russo, S.; et al. The KCNQ1OT1 imprinting control region and non-coding RNA: New properties derived from the study of Beckwith-Wiedemann syndrome and Silver-Russell syndrome cases. Hum. Mol. Genet. 2012, 21, 10-25. [CrossRef]

34. Nakashima, S.; Kato, F.; Kosho, T.; Nagasaki, K.; Kikuchi, T.; Kagami, M.; Fukami, M.; Ogata, T. Silver-Russell syndrome without body asymmetry in three patients with duplications of maternally derived chromosome 11p15 involving CDKN1C. J. Hum. Genet. 2015, 60, 91-95. [CrossRef] 